\title{
TRIM3 Facilitates Estrogen Signaling and Modulates Breast Cancer Cell Progression
}

\section{Beibei Wang}

Xinxiang Medical University

Xiaojing Tan

Dong ying People's Hospital

Le Wu

Huazhong Agriculture University

\section{Peng Su}

Shandong University

\section{Xin Li}

Xinxiang Medical University

Huijie Yang

Xinxiang Medical University

\section{Yuqing Cai}

Xinxiang Medical University

Xiao Yang

Xinxiang Medical University

Zhongbo Li

Xinxiang Medical University

Cheng Yan

Xinxiang University

Yan Xia

Xinxiang Medical University

Chenmiao zhang

Xinxiang Medical University

Zhiguo Niu

Xinxiang Medical University

\section{Qi Cao}

Xinxiang Medical University

\section{Yinlu Ding}

Shandong University

\section{Zhipeng Zhou}

Huazhong Agriculture University

Qingsong Huang 
Xinxiang Medical University

Ting Zhuang ( 77090993@qq.com )

Xinxiang Medical University https://orcid.org/0000-0002-6308-1253

\section{Primary research}

Keywords: TRIM3, ER alpha, Breast cancer, Stabilize, Ubiquitin

Posted Date: August 2nd, 2021

DOI: https://doi.org/10.21203/rs.3.rs-709377/v1

License: (1) This work is licensed under a Creative Commons Attribution 4.0 International License. Read Full License 


\section{TRIM3 facilitates estrogen signaling and modulates breast cancer cell}

progression

Beibei Wang ${ }^{1 *}$, Xiaojing Tan ${ }^{2 *}$, Le Wu ${ }^{3 *}$, Peng Su${ }^{4 *}$, Xin Li ${ }^{1}$, Huijie Yang ${ }^{1}$, Yuqing Cai ${ }^{1}$, Xiao Yang ${ }^{1}$, Zhongbo $\mathrm{Li}^{1}$, Cheng Yan ${ }^{5}$, Yan Xia ${ }^{1}$, Chenmiao Zhang ${ }^{1}$, Zhiguo Niu ${ }^{1}$, Qi $\mathrm{Cao}^{1}$, Yinlu Ding ${ }^{6 \#}$, Zhipeng Zhou ${ }^{7 \#}$, Qingsong Huang ${ }^{1 \#}$ and Ting Zhuang ${ }^{1 \#}$

\section{Author details}

${ }^{1}$ Xinxiang Key Laboratory of Tumor Migration, Invasion and Precision Medicine, Henan Key Laboratory of Immunology and Targeted Drugs, School of Laboratory Medicine, Henan Collaborative Innovation Center of Molecular Diagnosis and Laboratory Medicine, Xinxiang Medical University, Xinxiang, P.R. China

2Department of Oncology, Dong Ying People's Hospital, Shandong Province, P.R. China

${ }^{3}$ College of informatics, Huazhong Agricultural University, Wuhan, 430070, Hubei Province, P.R. China

${ }^{4}$ Department of Pathology, Shandong University, Qilu Hospital, Jinan, P.R. China ${ }^{5}$ School of Medicine, Xinxiang University, Xinxiang, 453003 Henan P.R. China ${ }^{6}$ Department of General Surgery, The Second Hospital, Cheeloo College of Medicine, Shandong University, Shandong Province, P.R. China

${ }^{7}$ College of Life Science and Technology, Huazhong Agricultural University, Wuhan, 430070, Hubei Province, P.R. China

*Beibei Wang, Xiaojing Tan, Le Wu and Peng Su contribute equally to this study.

\section{\#Corresponding author}

Ting Zhuang

Xinxiang Medical University, School of Laboratory Medicine, Henan Province, China, Phone: +86 17630701983, Email: Ting.zhuang@xxmu.edu.cn

\section{Qingsong Huang}

Xinxiang Medical University, School of Laboratory Medicine, Henan Province, China, Phone: +86 18737367105, Email: xxmuhqs@163.com

\section{Zhipeng Zhou}

College of Life Science and Technology, Huazhong Agricultural University, Wuhan, 430070, Hubei Province, P.R. China, Phone: + 13488881319, Email: zhouzhipeng@mail.hzau.edn.cn 
$40 \quad$ Yinlu Ding

41 Department of general surgery, the Second Hospital, Cheeloo College of Medicine,

42 Shandong University, Jinan, China, 250033, Phone: +86 15153169369, Email:

43 dingyinlu@126.com

44

45 \#Contributing author

46 Beibei Wang: 1733152857@qq.com

47 Xiaojing Tan: txj320@126.com

48 Le Wu: 3140575572@qq.com

49 Peng Su: supeng820125@163.com

50 Xin Li: lixin12036@163.com

51 Huijie Yang: gyh20200502@163.com

52 Yuqing Cai: 2826404271@qq.com

53 Xiao Yang: 775013101@qq.com

54 Zhongbo Li: 735396587@qq.com

55 Cheng Yan: yanchengxx@163.com

56 Yan Xia: xy18707149751@163.com

57 Chenmiao Zhang: zhangchenmiao1225@163.com

58 Zhiguo Niu: niuzhiguo@xxmu.edu.cn

59 Qi Cao: qi.cao@xxmu.edu.cn

60

61 Running title: TRIM3 stabilizes ER alpha in breast cancer

62

63 Key words: TRIM3, ER alpha, Breast cancer, Stabilize, Ubiquitin

64

65

Abstract

Background: Breast cancer ranks NO.1 in women cancer incidence worldwide, while $70 \%$ of breast cancers are estrogen receptor (ER) alpha positive. Compared with ER alpha negative breast cancer, which is more aggressive and shorter prognosis, ER alpha positive breast cancer could be well-controlled by endocrine therapy. Most of ER alpha positive breast cancer patients could benefit from selective ER alpha modulators, such as tamoxifen. However, approximately half of them will eventually develop endocrine resistance, making it an important clinical issue in

73 breast cancer therapy. Thus, decoding the turnover of estrogen signaling, including

74 the control of ER alpha expression and stability, are critical to the improvement of 75 breast cancer therapeutics.

76 Methods: TRIM3 and ER alpha protein expression levels were measured by western

77 blot, while the ER alpha target genes were measured by real-time PCR. MTT assay

78 was used to measure cell viability. RNA sequencing was analyzed by Ingenuity 
Pathway Analysis. Identification of ER alpha signaling was accomplished with luciferase assays, real-time RT-PCR and Western blotting. Protein stability assay and ubiquitin assay was used to detect ER alpha protein degradation. The ubiquitin-based Immuno-precipitation based assays were used to detect the specific ubiquitination

83 manner happened on ER alpha.

84 Results: In our current study, we identified TRIM3 as an E3 ligase, which promotes

85 ER alpha signaling and breast cancer progression. TRIM3 depletion inhibits breast 86 cancer cell proliferation and invasion, while the unbiased RNA sequencing data 87 indicates that TRIM3 is required for the activation of estrogen signaling in whole 88 genomic scale. Molecular studies show that TRIM3 associates with ER alpha and 89 promotes ER alpha mono-ubiquitination.

90 Conclusion: our study provides a novel post-translational mechanism in estrogen 91 signaling. Modulation of TRIM3 expression or its function could be an interesting 92 approach for breast cancer treatment.

93

Key words: TRIM3, ER alpha, Breast cancer, Ubiquitin, Stability

\section{Introduction}

Breast cancer is the most common women cancer malignancies and the second most common cause of cancer-related death worldwide [1]. The genomic based profiling analysis showed that breast cancer can be classified into four groups: Luminal $A$, Luminal B, HER2 type and basal-like type [2]. Among the groups, Luminal A and B types could accounts for approximately two thirds of the patients and could benefit from endocrine therapy [3]. The selective estrogen receptor modulators (SERMs) have become the standard treatment for ER alpha positive patients [4]. However, more than half of the patients will develop endocrine therapy resistance, which is a major challenge for breast cancer treatments [5]. Although some cases lose the ER alpha expression in breast cancer cells, most of the endocrine resistant breast cancers still maintain ER alpha expression [6]. Thus it is required and necessary for scientists to characterize the resistance mechanism together with the internal mechanism that controls ER alpha expression and stability.

Estrogen receptor alpha (ER) belongs to the superfamily of nuclear receptors, which was initially cloned from MCF-7 cells in 1985 [7]. ER alpha protein is composed of 595 amino acids by three functional domains: DNA binding domain, transcriptional activation domain and ligand binding domain [8]. When ER alpha is activated by $17 \beta$-estrodiol (E2), the ER alpha protein could trans-locate into the nuclear and subsequently bind to the promoter regions of ER alpha target genes, which facilitates certain downstream target gene expression, such as PS2 and GREB1 [9]. Besides, 
118 the effect of ER alpha ligands, the ER alpha protein could also been regulated by

119 several post-translational modifications. The modifications could be widely distributed 120 over the ER alpha protein and affect ER alpha function in several ways. For example, 121 the acetylation of ER alpha protein by P300 could enhance ER alpha activity [10], 122 while the phosphorylation of ER alpha protein at Y537 sites by SRC kinase could 123 change ER alpha conformation and increase the ligand independent activity [11].

124 Recent studies reveal that several atypical ubiquitination manners could also play 125 important role in modulating ER alpha function. For example, our previous studies 126 showed that RNF31/SHARPIN modulates ER alpha mono-ubiquitination and 127 facilitates ER alpha stability in breast cancer cells $[12,13]$. Based on the previous 128 studies, we infer that the components of the ubiquitin-proteasome system, including 129 several E3 ubiquitin ligases, might control the ER alpha ubiquitination, turnover and 130 ER alpha target gene expression.

131

132 TRIM3 (Tripartite Motif Containing 3) is one RING finger protein, which was initially 133 founded to be a regulator for myosin function and facilitate the protein transportation 134 in cells $[14,15]$. Several studies showed decreased expression level of TRIM3 and 135 potential role as a tumor suppressor in quite a few human cancers [16-19]. However, 136 our data showed that TRIM3 specifically related to poor survival in endocrine therapy 137 patients. Our data demonstrated TRIM3 as one candidate factor in modulating 138 estrogen signaling in breast cancer cells. TRIM3 associates with ER alpha, facilitates 139 ER alpha stability possibly by inducing ER alpha mono-ubiquitination and enhances 140 ER alpha signaling activity. Our study uncovers a novel non-genomic regulation 141 between TRIM3 and ER alpha signaling for breast cancer progression.

\section{Materials and Methods}

146 MCF-7, T47D and HEK293 cells were acquired form American Type Culture 147 Collection (ATCC). MCF-7 and HEK293 were culture with Dulbecco's Modified 148 Eagle's Medium together with 4,5 g/L glucose and $4 \mathrm{mM} \mathrm{L-glutamine} \mathrm{(DMEM,} \mathrm{41965,}$ 149 Life Technologies) supplemented with 10\% Fetal Bovine Serum (FBS, 10270, Life 150 Technologies). T47D cells are cultured with RPMI-1640 (42401, Life Technologies)

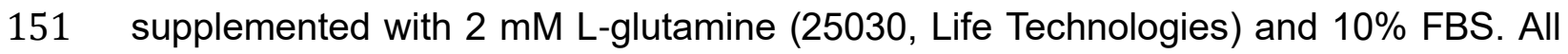
152 cell lines are characterized by cell line authentication. The cell line authentication via 153 Short Tandem Repeat (STR) is performed via PowerPlex 21 system. The STR data of 154 MCF-7 and T47D cell lines are found consistent with STR data in ATCC.

\section{Plasmids and siRNA}


157 The Flag-TRIM-3 plasmid was acquired from Origene. The ER alpha full and deletion 158 constructs were described in previous study [20]. The TRIM3 and ER alpha deletion 159 variants were sub-cloned from the original plasmids. The HA-Ub-K48, HA-UbKo, 160 HA-Ub-K63 and HA-Ub plasmids were used in previous study. The 161 Estrogen-Response-Element (ERE)-TK reporter and renilla plasmids were used in 162 previous study and are transfected with Lipofectamin 200 (1662298, Invitrogen). The 163 Lipofectamin 2000 (1662298, Invitrogen) was used for the plasmids transfection. 164 Small interfering RNAs were used for specific gene knocking-down. The TRIM3 165 siRNA sequences were: CAAACGAAAGGACAACCCAdTdT; 166 UGGGUUGUCCUUUCGUUUGdTdT and GCAACAACCAGUGUAUUCAdTdT; 167 UGAAUACACUGGUUGUUGCdTdT. The negative control siRNA sequences were: 168 UUCUCCGAACGUGUCACGUTT; ACGUGACACGUUCGGAGAATT. The RNAiMAX reagent (13778150, invitrogen) was used for siRNA transfection.

172 RNeasy plus mini kits were used to extract total RNA (Qiagen). Real-time PCR was 173 performed as previously described [21]. 36B4 was used for internal control. The 174 primer sequences were shown here. 36B4: F: GGCGACCTGGAAGTCCAACT; R: 175 CCATCAGCACCACAGCCTTC. GREB1 F: CGT GTG GTG ACT GGA GTA GC, R: 176 ACC TCT TCA AAG CGT GTC GT; ER F: GCT ACG AAG TGG GAA TGA TGA AAG, 177 R: TCT GGC GCT TGT GTT TCA AC; PS2 (TFF1) F: TGG GCT TCA TGA GCT CCT TC, R:TTC ATA GTG AGA GAT GGC CGG.

188 Fifty nM TRIM3 siRNA or siControl were transfected into MCF-7 or T47D cells. After twenty-four hours, cells were seeded into 12-well plates with $1 \% \mathrm{FBS}$. The cells were $100 \%$ confluence. The yellow pipette tips were applied for straight scratch. The wound distance was measured at indicated time points and normalized with starting 192 time point. The wound healing recovery was expressed as: [1-(Width of the wound at 193 a given time/width of the wound at $\mathrm{t}=0)] \times 100 \%$. 
196 Cell invasion capacity was measured using the modified two-chamber plates as 197 before. For invasion assay MCF-7 and T47D cells were transfected with 50 uM 198 TRIM3 siRNA or sControl. In order to stimulate invasion, the bottom wells were filled with complete medium, while the upper chambers were added with FBS-free medium.

200 After twelve hours, cells were carefully removed and the cells that invaded through the membrane were fixed and stained with Crystal Violet Staining solution. The cell numbers were counted by using a microscope.

\section{Western blotting}

Cells were harvested and lysed with RIPA buffer. Proteins were separated by electrophoresis on SDS-polyacrylamide gel electrophoresis (PAGE) and electro-transferred to PVDF membrane. The antibodies used in this study were listed here: Anti-TRIM3 (HAP043396, Sigma); Anti-ER alpha (D8H8, 8644, Cell signaling Technology); Anti-HA (MMS-101R, COVANCE); Anti-myc (9E10, ab32, Abcam); Anti-myc (Ab9106, Abcam); Anti-Actin (A5441, Sigma); Anti-Flag (20543-1-AP, Proteintech); Anti-GFP (Ab290, Abcam). Membranes were then washed with PBS for three times and incubated with secondary antibodies Peroxidase-Conjugated AffiniPure Goat Anti-Mouse IgG or Goat Anti-Rabbit IgG. Fluorescent signals were visualized with ECL system. (amersham imager 600, USA).

\section{Luciferase assay}

218 Dual-Luciferase Reporter kit (Promega, Germany). The ERE luciferase reporter was transfected together with the Renilla plasmid into the cells. Luciferase activity was measured after $24 \mathrm{~h}$.

\section{Co-immunoprecipitation assay} Immunoprecipitation was performed as described in previous study [20]. The MCF-7 total cell lysls were pre-cleared with rabbit $\operatorname{lgG}$ for $2 \mathrm{~h}$ and subsequently immunoprecipitated with ER alpha antibody (SC8005, Santa Cruz) over night, while rabbit IgG (Santa Cruz) was used as the negative control. The bounded protein was analyzed by Anti-TRIM3 (HAP043396, Sigma). For the overexpression experiment, HEK293 cells were transfected with 5ug GFP-TRIM3 (Full length or deletion domains) and ER alpha plasmid (Full length or deletion domains) in $10 \mathrm{~cm}$ dish. Cell lysates were pre-cleared with IgG and subsequently incubate with GFP (Ab290, Abcam) antibody, while rabbit IgG was used as the negative control. The bound proteins were

233 analyzed by western blotting.

\section{Poly-ubiquitination detection assay}


235 To directly detect the enriched overall ubiquitinated, K63-ubiquitinated,

236 mono-ubiquitinated and K48-ubiqutinated ER alpha from the cell extracts, HEK293

237 cells were transfected with 4 ug Ub, 4 ug K63 Ubi, 4 ug Ub-KO or 4 ug K48 Ubi

238 plasmid, 2 ug ER alpha together with 0.5 ug Myc-TRIM3 or Myc-vector. After $48 \mathrm{~h}$,

239 total protein was extracted and pre-cleared with 20ul protein A (santa cruz, SC-2001)

240 for $2 \mathrm{~h}$. The supernatant was collected and immunoprecipitated by ER alpha antibody.

241 Western blot with HA antibody was performed to detect specific ubiquitinated ER

242 alpha.

243 Immunofluorescence assay

244 MCF-7 cells were fixed with 4\% paraformaldehyde in PBS for 10 min, permeabilized 245 with $0.2 \%$ Triton X-100 for 5 min, and blocked by $5 \%$ BSA in PBS for $1 \mathrm{~h}$. A rabbit 246 Anti-TRIM3 (HAP043396, Sigma) and mouse anti-ER $\alpha$ monoclonal antibodies 247 (SC-56833) were used, followed by Alexa Flour 647 (Invitrogen) anti-rabbit antibody 248 and FITC-conjugated anti-mouse antibodies (Jackson ImmunoResearch, West Grove,

249 PA). As negative controls, the samples were incubated with the secondary antibodies 250 without primary antibodies. Images were acquired under conditions fulfilling the

251 Nyquist criterion using Nikon A+ laser scanning confocal system with a 60X oil NA1.4 252 objective and pinhole size of 1.0 Airy Unit. The acquired pictures were further 253 processed and assembled using ImageJ.

254

255

256

\section{Clinical breast tumor samples}

One hundred and twenty three formalin-fixed paraffin-embedded breast cancer samples were collected from the Department of Pathology, Shandong Qilu Hospital. All the breast tumors samples were examined by TRIM3 status, ER alpha status, PR status, HER2 status by pathological specialists. The pathological grade plus lymph node metastasis status of each sample was also examined by pathological specialists. This study was reviewed and approved by the Ethical Board at the Qilu Hospital of Shandong University with written informed consent from all the patients.

\section{Results:}

\section{TRIM3 is required for ER alpha positive breast cancer progression}

We utilized two independent siRNAs to test TRIM3 effect on breast cancer cells. The knocking down efficiency of siRNAs were shown in Figure 1A. The WST-1 assay showed that TRIM3 knocking down decreased the speed of cell growth in MCF-7 and T47D cells (Fig. 1B-1C). We further investigated the role of TRIM3 in cell migration. The wound-healing assay showed that TRIM3 depletion inhibited the wound closure speed in both MCF-7 and T47D cells (Fig. 1D-1E). The trans-well assay indicated that TRIM3 depletion hampered the capability of cell migration in both MCF-7 and T47D cells (Fig.1F-1G). All these experiments might indicate the oncogenic role of 
274 TRIM3 in ER positive breast cancer cells.

275

\section{TRIM3 modulates estrogen signaling in breast cancer cells}

We further investigated the role of TRIM3 in whole genomic scale. The RNA sequencing analysis showed that TRIM3 depletion inhibited several signaling, including ER alpha signaling (Fig. 2A). The heat map data showed that TRIM3 depletion affected a group of ER alpha signature genes, including PS2 and PR (Fig. 2B). Western blotting assay showed that TRIM3 depletion inhibited ER alpha protein level in MCF-7 cells (Fig. 2C). Further QPCR experiments showed that TRIM3 depletion reduced ER alpha classical target gene expression, including PS2 and GREB1. We further test TRIM3 effect on ER alpha signaling in both vehicle and E2-treated conditions. TRIM3 depletion could decrease ER alpha protein level and ER alpha target gene expression in vehicle and E2-treated conditions in MCF-7 cells (Fig. 2E-2F). In order to determine if TRIM3 knockdown could affect ER alpha transcriptional activity, we measure estrogen response element (ERE) luciferase activity in MCF-7 cells. The luciferase assay shows that TRIM3 depletion decreases ERE luciferase activity in MCF-7 cells (Fig. 2G).

294 From the survival data analysis, we observed that ER alpha expression correlated with poor survival in endocrine therapy patients (Fig. 3A)

296 (https://kmplot.com/analysis/). We further analyzed the expression relation between

297 TRIM3 and ER alpha classical target genes. From TCGA database, we observed that

298 TRIM3 correlated with TFF1/GREB1 expression in 1080 breast tumor samples (Fig. 3B-C) (https://tcga-data.nci.nih.gov/tcga/). In order to investigate the correlation between TRIM3 expression and breast cancer molecular biomarkers, 123 breast cancer tissues were collected for immunohistochemistry $(\mathrm{IHC})$ analysis. We examined the protein expression levels including TRIM3, ER alpha, PR and HER2 (Fig. 3D). Besides, the pathological grade and lymph node metastasis data were also collected. The IHC analysis implicate that TRIM3 expression correlates with ER alpha protein levels $(P<0.001)$ and $P R$ protein levels $(P<0.001)$. Besides, TRIM3 expression levels were also correlated with lower pathological grade $(P=0.04)$ (Fig. 3E).

\section{TRIM3 associates with ER alpha and modulates ER alpha stability} We further examined the localization of TRIM3 and ER alpha in breast cancer cells. The immuno-staining indicated that ER alpha was mainly located in the nuclear, while TRIM3 located both in the cytosol and nuclear (Fig. 4A). The endogenous 
313 immuno-precipitation showed that TRIM3 could interact with ER alpha in MCF-7 cells

314 (Fig.4B). Since TRIM3 could associate with ER alpha in breast cancer cells, we 315 further investigated the biological effect of such interaction. Since ER alpha could 316 regulate its own expression, making it difficult to distinguish direct effects of TRIM3 on 317 ER alpha mRNA or protein levels in the cell line. We utilized HEKC293 cells to 318 investigate the mechanism. Co-transfection of ER alpha and TRIM3 in HEK293 cells

319 showed that TRIM3 could increase ER alpha protein level (Fig. 4C), which effect 320 could be minimized with the presence of the proteasome inhibitor MG132 (Fig. 4D). 321 The protein half-life assay showed that TRIM3 could increase the protein stability of 322 ER alpha (Fig. 4E-4F).

323

TRIM3 associates with ER alpha DNA binding domain via its Filamin/NHL domain

326 We further characterize the interaction domains between ER alpha and TRIM3. ERa

327 is composed of three functional domains: AF1 domain, DNA binding domain and AF2 328 domain, while TRIM3 contains RING domain, B1/B2 domain, CC domain and 329 Filamin/NHL domain. We made the ERa variants (AF1 domain, AF1+DBD domains, 330 AF2 domain and $A F 2+D B D$ domains) and TRIM3 variants ( $\triangle R I N G+\triangle B 1 / 2$ domains, $331 \Delta$ Filamin/NHL domain, $\triangle$ Filamin/NHL domain+CC domains) (Fig. 5A). 332 Immuno-precipitation implicates that the DBD domain of ER alpha was required for its 333 interaction with TRIM3 (Fig. 5B-5C), while the Filamin/NHL domain of TRIM3 was 334 required for its interaction with ER alpha (Fig. 5D-5E). However, co-transfection of ER 335 alpha with TRIM3 variants showed that only the full length of TRIM3 could exert its 336 stabilization function on ER alpha protein (Fig.5F).

338 TRIM3 facilitates K63-linked ubiquitination and mono-ubiquitination of ER 339 alpha.

340 Since TRIM3 is a putative E3 ubiquitin ligase, we further investigated the role of 341 TRIM3 on ER alpha ubiquitination. The ubiquitination-based immuno-precipitation 342 shows that TRIM3 could inhibit ER alpha overall poly-ubiquitination (Fig. 6A). Since 343 K48-linked ubiquitination is the most common degradation manner, we examined the 344 TRIM3 effect on K48-linked ubiquitination of ER alpha, which implicated that TRIM3 345 could inhibit K48-linked ubiquitination of ERa (Fig. 6B). Besides, since K63-linked 346 ubiquitinaiton or mono-ubiquitination of ER alpha could increase ER alpha stability 347 and its signaling activity, we further analyzed effect of TRIM3 on ER alpha 348 ubiquitination on these two forms. The data indicated that TRIM3 could significantly 349 increase K63-linked poly-ubiquitination and mono-ubiquitination on ER alpha protein 350 (Fig. 6C-6D). 
353 In our current study, we identified one RING family protein TRIM3 in modulating ER 354 alpha signaling via its stability (Fig. 6E). Clinical data analysis indicated the positive 355 correlation between TRIM3 and ER alpha protein level in IHC human sample. 356 Besides, TRIM3 correlated with poor survival in endocrine therapy patients. Our study provided a non-genomic regulation on ER alpha stability control. Based on these study, we can propose that the modulating or inhibition of TRIM3 protein could an interesting strategy for ER alpha positive breast cancer treatments.

ER alpha gene was firstly discovered 30 years ago [7]. Based on the current understanding about breast cancer, ER alpha signaling is the main driver for two thirds of the breast cancer patients [22]. Although the gene amplification or mutation of ER alpha is not common in breast cancer, the increased expression could be observed in most of the breast tumors compared with normal breast tissue [23]. Thus, targeting ER alpha signaling is an excellent strategy for breast cancer, while the selective modulator of ER alpha, including tamoxifen, demonstrated a great success in inhibiting ER alpha signaling and breast cancer progression [22]. However, the occurrence of endocrine resistance is a headache problem for breast cancer therapy. Interestingly, most of the endocrine resistant breast tumors still maintain ER alpha expression, which lends to the possible involvement of ER alpha in drug resistance. Several confirmed and possible mechanisms indicate that the crosstalk between ER alpha and other signaling pathways or ER alpha modifications play important roles in medicating endocrine resistance. For example, ER alpha could trans-activate several growth factor pathways, including IGFR and AKT signaling, while the activation of these signaling cascades promotes the phosphorylation of ER alpha and facilitates ER alpha trans-activation [24]. Besides, recent studies reveal that the protein modifications of ER alpha could stabilize ER alpha or enhance ER alpha transcriptional activity in breast tumors [10,25]. Thus, modulating of ERa expression and stability could be a promising strategy for breast cancer therapeutics and endocrine resistance.

There are about 500-1000 E3 ubiquitin ligases, which could be divided into four groups: HECT type, RING type, U-box type and PHD-finger type [26]. Among these, the RING family is the biggest and the function is not totally clear. Interestingly, recent studies showed that some RING family E3 ligases preferred to catalyze in atypical ubiquitin manner, which did not necessarily lead to degradation [27]. Several RING family members participate in ERa signaling activation and breast cancer progression via non-degradation related ubiquitinations. For example, RNF8 was shown to associate with ER alpha, promote ER alpha mono-ubiquitination and its signaling 
391 transduction [28]. Besides, our previous work also identified a few E3 ubiquitin

392 ligases in modulating ER alpha stability via non-genomic manner, including TRIM56

393 and RNF31 [29, 30].

394

395 TRIM3 belongs to the RING finger family proteins and is comprised of zinc-binding

396 domain, RING domain, B1/2 domain and coiled region [19]. TIRM3 was firstly

397 reported to interact with myosin and promoted the transportation of the target proteins

398 [15]. TRIM3 decreased the expression in several human cancers, including gastric

399 cancer, colon cancer and liver cancer [18, 19, 31, 32]. However, even TRIM3 was

400 suggested as a tumor suppressor protein in several cancer types, we did not observe

401 any dramatic expression change in breast cancer compared with normal breast tissue,

402 which might indicated the uncertain role or dual roles of TRIM3 in breast cancer. Our

403 molecular study revealed that TRIM3 could facilitate ER alpha signaling, promoting

404 cell proliferation and invasion in breast cancer. Our finding indicates TRIM3 plays a

405 oncogenic role in ER alpha positive breast cancer cells, which is opposite to previous

406 studies $[18,19]$. This interesting finding not only increases the understanding of ER

407 alpha post-translational modifications but also implicates the multi-face of TRIM3 in

408 different cancer background.

409

410 In conclusion, we identified an interesting E3 ligase TRIM3 in facilitating ER alpha

411 signaling in breast cancer cells. TRIM3 could promote breast cancer cell invasion and

412 proliferation via stabilizing ER alpha protein. As a novel modulator of ER alpha

413 signaling, disturbing TRIM3 activity or affecting TRIM3 expression could be a

414 plausible way to treat luminal types of breast cancer.

415

416 Public available clinical data analysis

417 Analysis of TRIM3 with clinical prognosis was carried out through KMPLOT database

418 (https://kmplot.com). Analysis of TRIM3 correlation with ER alpha target gene (TFF1

419 and GREB1) was carried out by TCGA database with 1080 breast cancer samples.

420 The analysis was carried out with "ggcorrplot" package in the statistical environment

421 R-3.6.1 version. The "ggcorrplot" package version is "ggcorrplot 0.1.3". The detailed

422 information of "ggcorrplot" can be found in the following link:

423 https://github.com/kassambara/ggcorrplot.

424

425

426 The global gene expression analysis (siControl and siTRIM3) was based on RNA

427 sequencing platform from BGI (Beijing Genomic Institute). The RNA sequence data

428 are deposited in the Gene Expression Omnibus (GEO) database (Assessing number:

429 GSE143610). Analysis was performed for differentially expressed genes $(P<0.01$ 
430 and fold change $>2$ ) by Ingenuity Pathway Analysis (IPA).

\section{Statistics}

Student's t-test, Pearson correlation coefficient, and Cox regression analysis were used for comparisons. A P-value of $<0.05$ was considered to be significant.

437 TRIM3: Tripartite Motif Containing 3

438 AF1: Transcriptional activation domain 1

439 DBD: DNA binding domain

440 AF2: Transcriptional activation domain 2

441 ER alpha: Estrogen receptor alpha

442 HER2: Human epidermal growth factor receptor 2

443 PR: Progesterone receptor

444 TBNC: Triple negative breast cancer

445 RBR: RING-between-RING domain

446 ZF: Zinc finger domain

447 EMT: Epithelial-mesenchymal transition

448 ATCC: American Type Culture Collection

\section{Declarations}

451 Ethics Approval and Consent to participate: This study was reviewed and 452 approved by the Ethical Board at Xinxiang Medical University. This usage of clinical 453 samples was reviewed and approved by the Ethical Board at the Qilu Hospital of 454 Shandong University with written informed consents from all the patients.

Consent for publication: All authors read the manuscript and agree for publication.

Availability of supporting data: The RNA sequence data are deposited in the Gene

463 Funding: The project was supported from the National Natural Science Foundation

464 of China (No. 81702725, Ting Zhuang); The Program for Science \& Technology 465 Innovation Talents in Universities of Henan Province (Grant No. 21HASTIT049, Ting 466 Zhuang); Key R\&D programs in Shandong (2019GSF108229, Yinlu Ding); The 467 National Natural Science Foundation of China (Grant No. U1804167; NO.81770721; 468 NO.81570624, Qingsong Huang); Key Scientific and Technological Projects of Henan 
469 Province (Grant No. 202102310024, Qingsong Huang); Huazhong Agricultural

470 University Scientific \& Technological Self-innovation Foundation (Zhipeng Zhou);

471 Henan University Science and Technology Innovation Team Support Program

472 (20IRTSTHN030); National Undergraduate Training Program for Innovation and

473 Entrepreneurship(S202010472039, Yuqing Cai).

474

475

Authors' contributions: BB.W, XJ.T L.W and P.S performed most of the bench

476

477 work. X.L, HJ.Y, YQ.C, X.Y, ZB.L, C.Y, Y.X, CM.Z, ZG.N and Q.C participated in

478 western blot, real time PCR work. YL.D, ZP.Z, QS.H and T.Z supervised the process

479

of the study and performed the manuscript writing.

Acknowledgement: We thank all the members of Xinxiang Key Laboratory of Tumor Migration, Invasion and Precision Medicine in Xinxiang University for sharing valuable material and research support.

485

1. Bray F, Ferlay J, Soerjomataram I, Siegel RL, Torre LA, Jemal A: Global cancer statistics 2018: GLOBOCAN estimates of incidence and mortality worldwide for 36 cancers in 185 countries. CA: a cancer journal for clinicians 2018, 68(6):394-424.

2. Onitilo AA, Engel JM, Greenlee RT, Mukesh BN: Breast cancer subtypes based on ER/PR and Her2 expression: comparison of clinicopathologic features and survival. Clinical medicine \& research 2009, 7(1-2):4-13.

3. Esakov EL, Hale J, Richards EG, Torre-Healy L, Gullapalli K, Trivedi D et al: Therapeutic strategies to induce ERalpha in luminal breast cancer to enhance tamoxifen efficacy. Endocrine-related cancer 2019, 26(8):689-698.

4. Chang BY, Kim SA, Malla B, Kim SY: The Effect of Selective Estrogen Receptor Modulators (SERMs) on the Tamoxifen Resistant Breast Cancer Cells. Toxicological research 2011, 27(2):85-93.

5. Musgrove EA, Sutherland RL: Biological determinants of endocrine resistance in breast cancer. Nature reviews Cancer 2009, 9(9):631-643.

6. Fan P, Jordan VC: New insights into acquired endocrine resistance of breast cancer. Cancer drug resistance 2019, 2:198-209.

7. Greene GL, Gilna P, Waterfield M, Baker A, Hort Y, Shine J: Sequence and expression of human estrogen receptor complementary DNA. Science 1986, 231(4742):1150-1154.

8. Renaud J, Bischoff SF, Buhl T, Floersheim P, Fournier B, Geiser M et al: Selective estrogen receptor modulators with conformationally restricted side chains. Synthesis and structure-activity relationship of 
ERalpha-selective tetrahydroisoquinoline ligands. Journal of medicinal chemistry 2005, 48(2):364-379.

9. Saha Roy S, Vadlamudi RK: Role of estrogen receptor signaling in breast

512 10. Hanstein B, Eckner R, DiRenzo J, Halachmi S, Liu H, Searcy B et al: p300 is a

11. Arnold SF, Obourn JD, Jaffe H, Notides AC: Phosphorylation of the human estrogen receptor on tyrosine 537 in vivo and by src family tyrosine kinases in vitro. Molecular endocrinology 1995, 9(1):24-33.

12. Zhu J, Zhuang $\mathrm{T}$, Yang $\mathrm{H}$, Li X, Liu H, Wang $\mathrm{H}$ : Atypical ubiquitin ligase RNF31: the nuclear factor modulator in breast cancer progression. BMC Cancer 2016, 16:538.

13. Tian Z, Tang J, Yang Q, Li X, Zhu J, Wu G: Atypical ubiquitin-binding protein SHARPIN promotes breast cancer progression. Biomed Pharmacother 2019, 119:109414.

14. Hung AY, Sung CC, Brito IL, Sheng M: Degradation of postsynaptic scaffold GKAP and regulation of dendritic spine morphology by the TRIM3 ubiquitin ligase in rat hippocampal neurons. PloS one 2010, 5(3):e9842.

15. Labonte D, Thies E, Pechmann Y, Groffen AJ, Verhage M, Smit AB et al: TRIM3 regulates the motility of the kinesin motor protein KIF21B. PloS one 2013, 8(9):e75603.

16. Huang XQ, Zhang XF, Xia JH, Chao J, Pan QZ, Zhao JJ et al: Tripartite motif-containing 3 (TRIM3) inhibits tumor growth and metastasis of liver cancer. Chinese journal of cancer 2017, 36(1):77.

17. Liu Y, Raheja R, Yeh N, Ciznadija D, Pedraza AM, Ozawa T et al: TRIM3, a tumor suppressor linked to regulation of p21(Waf1/Cip1.). Oncogene 2014, 33(3):308-315.

18. Piao MY, Cao HL, He NN, Xu MQ, Dong WX, Wang WQ et al: Potential role of TRIM3 as a novel tumour suppressor in colorectal cancer (CRC) development. Scandinavian journal of gastroenterology 2016, 51(5):572-582.

19. Raheja R, Liu Y, Hukkelhoven E, Yeh N, Koff A: The ability of TRIM3 to induce growth arrest depends on RING-dependent E3 ligase activity. The Biochemical journal 2014, 458(3):537-545.

20. Zhuang T, Yu S, Zhang L, Yang H, Li X, Hou Y et al: SHARPIN stabilizes estrogen receptor alpha and promotes breast cancer cell proliferation. Oncotarget 2017, 8(44):77137-77151. 
547 21. Yang H, Yu N, Xu J, Ding X, Deng W, Wu G et al: SMURF1 facilitates

$548 \quad$ estrogen receptor a signaling in breast cancer cells. $J$ Exp Clin Cancer 549 Res 2018, 37(1):24.

550 22. Hayashi S, Yamaguchi Y: Estrogen signaling pathway and hormonal 551 therapy. Breast cancer 2008, 15(4):256-261.

552 23. Shaaban AM, Sloane JP, West CR, Foster CS: Breast cancer risk in usual 553 ductal hyperplasia is defined by estrogen receptor-alpha and Ki-67 554

24. Bunone G, Briand PA, Miksicek RJ, Picard D: Activation of the unliganded estrogen receptor by EGF involves the MAP kinase pathway and direct phosphorylation. The EMBO journal 1996, 15(9):2174-2183.

25. Wang C, Fu M, Angeletti RH, Siconolfi-Baez L, Reutens AT, Albanese $C$ et al: Direct acetylation of the estrogen receptor alpha hinge region by $\mathrm{p} 300$ regulates transactivation and hormone sensitivity. The Journal of biological chemistry 2001, 276(21):18375-18383.

26. Metzger MB, Hristova VA, Weissman AM: HECT and RING finger families of E3 ubiquitin ligases at a glance. Journal of cell science 2012, 125(Pt 3):531-537.

27. Deshaies RJ, Joazeiro CA: RING domain E3 ubiquitin ligases. Annual review of biochemistry 2009, 78:399-434.

28. Wang $\mathrm{S}$, Luo $\mathrm{H}$, Wang $\mathrm{C}$, Sun $\mathrm{H}$, Sun $\mathrm{G}$, Sun $\mathrm{N}$ et al: RNF8 identified as a co-activator of estrogen receptor alpha promotes cell growth in breast cancer. Biochimica et biophysica acta Molecular basis of disease 2017, 1863(6):1615-1628.

29. Zhu J, Zhao C, Kharman-Biz A, Zhuang T, Jonsson P, Liang $\mathrm{N}$ et al: The atypical ubiquitin ligase RNF31 stabilizes estrogen receptor alpha and modulates estrogen-stimulated breast cancer cell proliferation. Oncogene 2014, 33(34):4340-4351.

30. Xue M, Zhang K, Mu K, Xu J, Yang H, Liu Y et al: Regulation of estrogen signaling and breast cancer proliferation by an ubiquitin ligase TRIM56. Oncogenesis 2019, 8(5):30.

31. Chen G, Kong J, Tucker-Burden $\mathrm{C}$, Anand $\mathrm{M}$, Rong $\mathrm{Y}$, Rahman $\mathrm{F}$ et al: Human Brat ortholog TRIM3 is a tumor suppressor that regulates asymmetric cell division in glioblastoma. Cancer research 2014, 74(16):4536-4548.

32. Zhu J, Wu G, Ke Z, Cao L, Tang M, Li Z et al: Targeting TRIM3 deletion-induced tumor-associated lymphangiogenesis prohibits lymphatic metastasis in esophageal squamous cell carcinoma. Oncogene 2019, 38(15):2736-2749. 
588 Figure 1: TRIM3 is required for ER alpha positive breast cancer progression.

589 A: TRIM3 knocking down efficiency in MCF-7 cells. MCF-7 cells were transfected 590 with TRIM3 siRNA. After $48 \mathrm{~h}$, TRIM3 mRNA levels were determined by QPCR.

591 B: TRIM3 depletion inhibited MCF-7 cells proliferation. MCF-7 cells were transfected

592 with siControl or siTRIM3. After 24 hours, the WST assay was used to determine the 593 cellar metabolic activity at indicated time points after infection. Experiments were 594 done in triplicates. ${ }^{*} \mathrm{P}<0.05 ;{ }^{* *} \mathrm{P}<0.01 ;{ }^{* * *} \mathrm{P}<0.001$ for cell growth comparison.

595 C: TRIM3 depletion inhibited T47D cells proliferation. T47D cells were transfected 596 with siControl or siTRIM3. After 24 hours, the WST assay was used to determine the 597 cellar metabolic activity at indicated time points after infection. Experiments were 598 done in triplicates. ${ }^{*} \mathrm{P}<0.05 ;{ }^{* *} \mathrm{P}<0.01 ;{ }^{* * *} \mathrm{P}<0.001$ for cell growth comparison.

599 D and E: Wound-healing assay indicated that TRIM3 depletion inhibited breast cell 600 migration capacity. MCF-7 or T47D cells were transfected with siControl or siTRIM3. 601 After 24 hours, cells were transfected with siTRIM3 or siControl. Quantification of 602 wound closure at the indicated time points. Data are presented as $\pm S D$. ${ }^{*}, P<0.01$, $603{ }^{* * *}, P<0.001$ (student's t-test).

604 F and G: TRIM3 depletion inhibited breast cancer cell migration capacity. MCF-7 or 605 T47D cells were transfected with siControl or siTRIM3. After 24 hours, cells were 606 transfected with siTRIM3 or siControl. After another 24 hours, cancer cells were 607 seeded into the chamber for trans-well assay. The cell number was counted and Data 608 are presented as $\pm \mathrm{SD}$. ${ }^{* *}, \mathrm{P}<0.01,{ }^{* * *}, \mathrm{P}<0.001$ (student's t-test).

Figure 2: TRIM3 modulates estrogen signaling in breast cancer cells.

611 A: Top 10 signaling pathways significantly decreased by TRIM3 depletion in MCF7

612 cells. The pathway-enrichment analysis was used by the threshold $P<0.001$ and fold

613 change $>2$ to derive regulated genes. TRIM3 was depleted by siRNA (mix of siTRIM3

$614 \# 1$ and siTRIM3 \#2) or treated with siControl. After 48 hours, the whole mRNA was

615 extracted for RNA sequence analysis. The siControl and siTRIM3 were done in 616 triplicates.

617 B: The heat-map graph showed the ER alpha regulating genes, which is significantly 618 inhibited by TRIM3 depletion in MCF-7 cells.

619 C: TRIM3 consumption decreased ER alpha protein levels via two independent 620 siRNAs in MCF-7 cells. MCF-7 cells were transfected with siControl or siTRIM3. After 62148 hours, cells were harvested for western blot analysis. TRIM3 and ER alpha protein 622 levels were determined by Western blot. Actin was used as internal control.

623 D: TRIM3 consumption decreased ER alpha target gene expression via two 624 independent siRNAs in MCF-7 cells. MCF-7 cells were transfected with siControl or 
625 siTRIM3. After 48 hours, total RNA was extracted for gene expression analysis.

$626{ }^{*} \mathrm{P}<0.05 ;{ }^{* *} \mathrm{P}<0.01 ;{ }^{* * *} \mathrm{P}<0.001$ for target gene expression comparison.

627 E: TRIM3 depletion decreased ER alpha protein levels in both vehicle and E2-treated

628 conditions in MCF-7 cells. MCF-7 cells were transfected with siTRIM3 or siControl.

629 After $48 \mathrm{~h}$, cells were treated with either ethanol or 10nM estradiol for $6 \mathrm{~h}$. TRIM3 and

630 ER alpha protein levels were determined by Western blot analysis. Actin was used as 631 internal control.

632 F: TRIM3 depletion decreased ER alpha target genes in both vehicle and E2-treated 633 conditions in MCF-7 cells. MCF-7 cells were transfected with siTRIM3 or siControl. 634 After $48 \mathrm{~h}$, cells were treated with either ethanol or 10nM estradiol for $6 \mathrm{~h}$. Total RNA 635 was prepared and the expression of the endogenous ER alpha target genes, PS2, 636 GREB1, and PKIB were determined by qPCR. Shown are the results from three 637 experiments. ${ }^{*} \mathrm{P}<0.05$; ${ }^{* *} \mathrm{P}<0.01$; ${ }^{* *} \mathrm{P}<0.001$ for target gene expression comparison. 638 G: TRIM3 depletion affected ERE-luciferase activity in MCF-7 cells. MCF-7 cells were 639 transfected with siTRIM3 or siControl together with ERE luciferase reporter plasmid. 640 Cells were treated with $10 \mathrm{nM}$ estradiol or vehicle. Luciferase activity was measured $64148 \mathrm{~h}$ after transfection. Shown are the results from three experiments. ${ }^{*} \mathrm{P}<0.05$; ${ }^{* *}$ $642 \mathrm{P}<0.01 ;{ }^{* *} \mathrm{P}<0.001$ for luciferase activity comparison.

644 Figure 3: TRIM3 correlates with ER alpha protein level and its target genes 645 expression in breast cancer samples.

646 A: TRIM3 correlated with poor endocrine therapy outcome in public available 647 database (https://kmplot.com).

648 B and C: Public available data shows that TRIM3 was reversely correlated with ER

649 alpha target genes: GREB1 and TFF1 (https://www.cbioportal.org).

650 D: Example tumor cases showing that TRIM3 reversely correlated with ER alpha and 651 PR protein in IHC

652 E: Statistical analysis of TRIM3 correlation with ER alpha in 123 human breast tumor 653 samples.

654

655 Figure 4: TRIM3 associates with ER alpha and modulates ER alpha stability.

656 A: Intracellular localization analysis of ER alpha and TRIM3 by immunofluorescence 657 assay. MCF-7 cells were cultured in normal medium before fixation. Intracellular 658 localization of ER alpha (red) and TRIM3 (green) were shown. Nuclei (blue) were 659 stained with 4',6-diamidino-2-phenylindole (DAPI).

660 B: Co-IP assay revealed association between endogenous ER alpha and TRIM3 661 protein in MCF-7 cells. MCF-7 cells were harvested with RIPA lysis buffer. CO-IP was 662 performed using antibody as indicated.

663 C: TRIM3 could stabilize ER alpha protein. HEK293 cells were transfected with 1 ug 
664 ER alpha together with different amounts of TRIM3 plasmids. After $24 \mathrm{~h}$, cell lysates 665 were prepared for Western blot analysis. The results are representative for three 666 independent experiments.

667 D: In the presence of the proteasome inhibitor MG132, the stabilization effect of 668 TRIM3 on ER alpha did not further increase ER alpha protein levels. HEK293 cells 669 were transfected with TRIM3 and ER alpha plasmids. After $24 \mathrm{~h}$, cells were treated

670 with $10 \mathrm{uM} \mathrm{MG132/vehicle} \mathrm{for} 6 \mathrm{~h}$. Cell lysates were prepared for Western blot 671 analysis. The results are representative for three independent experiments.

672 E: TRIM3 increases ER alpha half-life in HEK293 cells. HEK293 cells were 673 transfected with HA-ER $\alpha$ plasmid and Myc-tag or Myc-TRIM3 plasmids. After $24 \mathrm{~h}$, 674 cells were treated with $100 \mu \mathrm{M}$ cycloheximide/vehicle for indicated times. Cell lysates

675 were prepared for Western blot analysis. The results are representative for three 676 independent experiments. The ER alpha relative density was measured by Image $\mathrm{J}$ 677 software.

Figure 5: TRIM3 associates with ER alpha DNA binding domain via its Filamin/NHL domain.

A: ER alpha domain structure and deletion mutants were used in the study and TRIM3 full length and deletion mutants were used in the study. B and C: ER alpha interacted with TRIM3 through its DBD domain. HEK293 cells were transfected with $2 \mu \mathrm{g}$ Myc-TRIM3 together with HA-ER alpha full length or mutants $(\triangle \mathrm{AF} 1, \triangle \mathrm{AF} 1+\triangle \mathrm{DBD}, \triangle \mathrm{AF} 2$ and $\triangle \mathrm{AF} 2+\triangle \mathrm{DBD})$. After $24 \mathrm{~h}$, cells were harvested with NP-40 lysis buffer. CO-IP was performed using Myc antibody. The possible interacted ER alpha domains were detected by HA antibody.

D and E: The Filamin/NHL domain was required for TRIM3 to interaction with ER GFP-TRIM3 full length or mutants ( $\triangle \mathrm{N}$-RING domain, $\triangle \mathrm{RING}+\Delta \mathrm{CC}$ domain, $\Delta$ Filamin/NHL domain, $\Delta$ Filamin/NHL $+\Delta C$ C domian). After $24 \mathrm{~h}$, cells were harvested with NP-40 lysis buffer. CO-IP was performed using HA antibody. The possible interacted TRIM3 domains were detected by GFP antibody. HEK293 cells were transfected with $2 \mu \mathrm{g}$ Flag- ER alpha and $0.5 \mu \mathrm{g}$ GFP-TRIM3 full length or mutants $(\Delta \mathrm{N}-\mathrm{RING}$ domain, $\Delta \mathrm{RING}+\Delta \mathrm{CC}$ domain, $\Delta$ Filamin/NHL domain, $\Delta$ Filamin/NHL $+\Delta C C$ domian). The ER alpha protein levels were detected via western

700 Figure 6: TRIM3 facilitates K63-linked ubiquitination and mono-ubiquitination 701 of ER alpha.

702 A: TRIM3 decreased poly-ubiquitination of ER alpha. HEK293 cells were transfected 
703 with $2 \mu \mathrm{g}$ ER alpha plasmid, $0.5 \mu \mathrm{g} \mathrm{HA} \mathrm{Ub}$ plasmid and $0.5 \mu \mathrm{g}$ GFP-tag or 704 GFP-TRIM3 plasmids. The cell extracts were immunoprecipitated with HA antibody. 705 The poly-ubiquitinated ER alpha was detected via western blotting analysis.

706 B: TRIM3 decreased K48-linked poly-ubiquitination of ER alpha. HEK293 cells were 707 transfected with $2 \mu \mathrm{g}$ ER alpha plasmid, $0.5 \mu \mathrm{g} \mathrm{HA-K48} \mathrm{Ubi} \mathrm{plasmid} \mathrm{and} 0.5 \mu \mathrm{g}$ 708 GFP-tag or GFP-TRIM3 plasmids. The cell extracts were immunoprecipitated with HA 709 antibody. The K48 specific poly-ubiquitinated ER alpha was detected via western 710 blotting analysis.

711 C: TRIM3 promoted K63-linked poly-ubiquitination of ER alpha. HEK293 cells were 712 transfected with $2 \mu \mathrm{g}$ ER alpha plasmid, $0.5 \mu \mathrm{g}$ HA-K63 Ubi plasmid and $0.5 \mu \mathrm{g}$ 713 GFP-tag or GFP-TRIM3 plasmids. The cell extracts were immunoprecipitated with HA 714 antibody. The K63 specific poly-ubiquitinated ER alpha was detected via western 715 blotting analysis.

716 D: TRIM3 promoted mono-ubiquitination of ER alpha. HEK293 cells were transfected 717 with $2 \mu \mathrm{g}$ ER alpha plasmid, $0.5 \mu \mathrm{g} \mathrm{HA}-U \mathrm{~b}-\mathrm{KO}$ plasmid and $0.5 \mu \mathrm{g}$ GFP-tag or 718 GFP-TRIM3 plasmids. The cell extracts were immunoprecipitated with HA antibody.

719 The mono-ubiquitinated ER alpha was detected via western blotting analysis.

720 E: The hypothesis model of TRIM3 regulating ER alpha signaling in breast cancer:

721 TRIM3 interacted with ER alpha protein, stabilized ERa and facilitated its signaling

722 activation and breast cancer progression. 
A

\begin{tabular}{|c|}
\hline Suppressed Pathways by siTRIM3 \\
\hline Estrogen-mediated S-phase Entry \\
\hline Proteoglycans in cancer \\
\hline Focal adhesion \\
\hline Drug metabolism - cytochrome P450 \\
\hline Retinol metabolism \\
\hline Thyroid cancer \\
\hline Hippo signaling pathway \\
\hline Circadian rhythm \\
\hline Chemical carcinogenesis \\
\hline Trefoil Factors Initiate Mucosal Healing \\
\hline
\end{tabular}

C

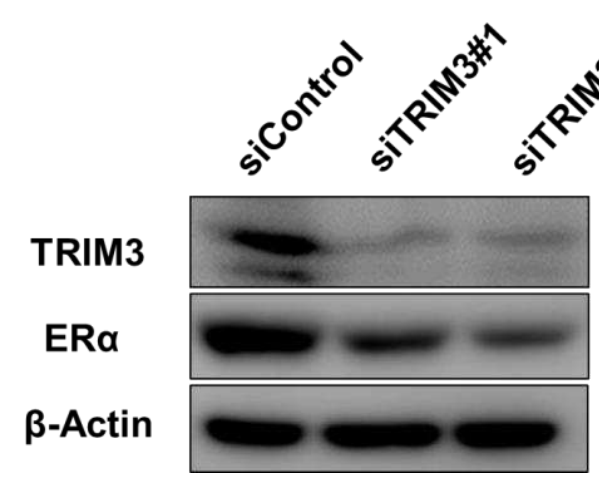

B

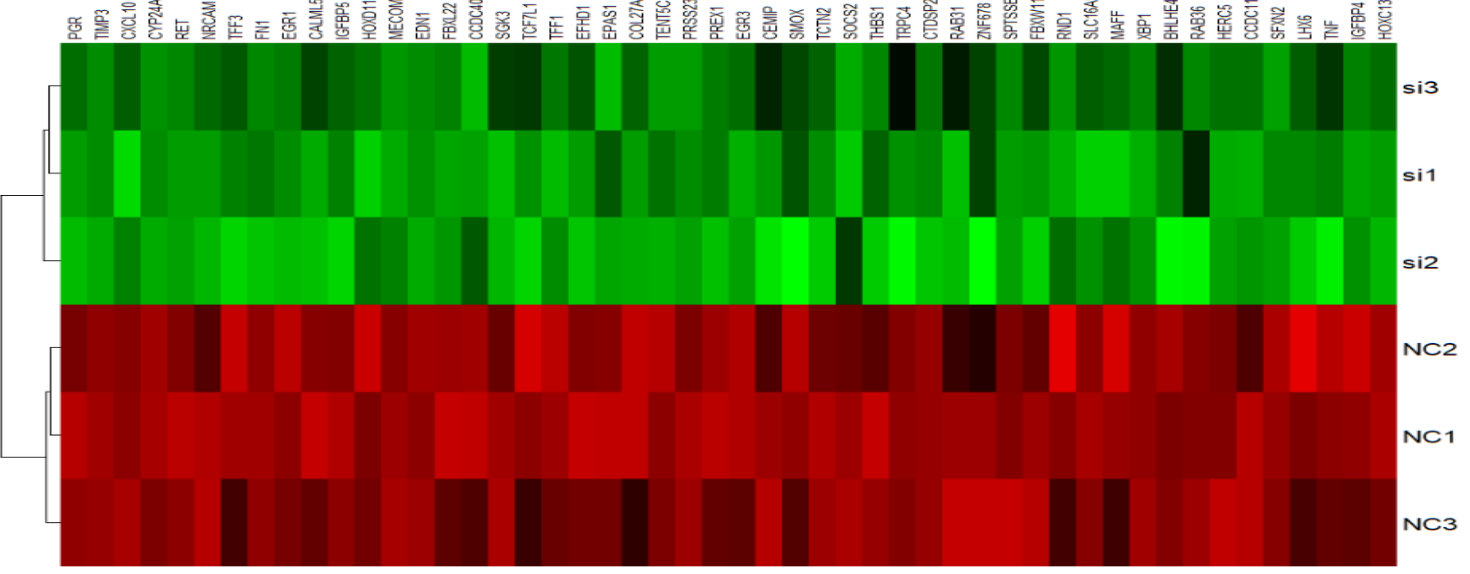

D

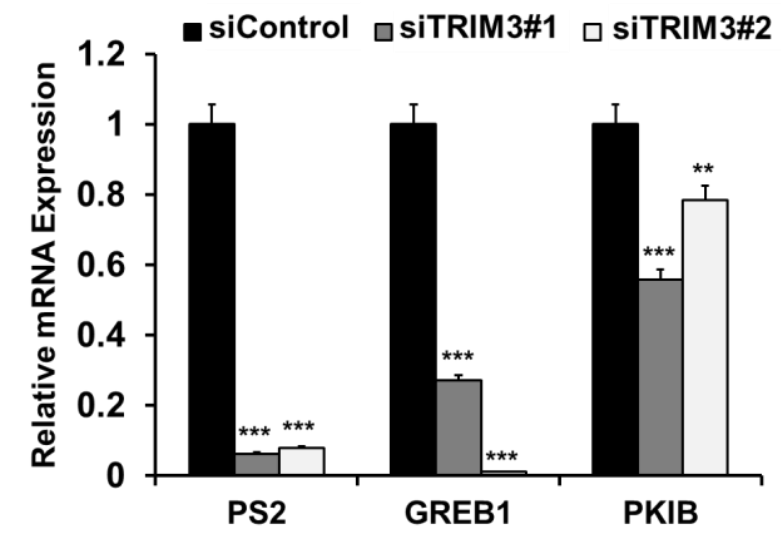

E

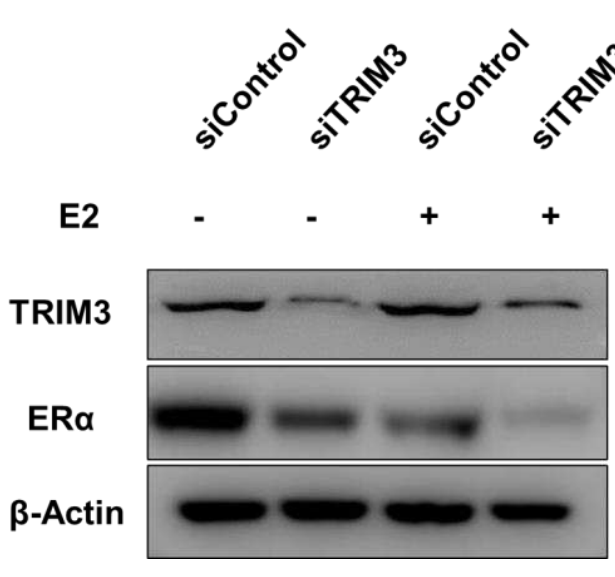

F

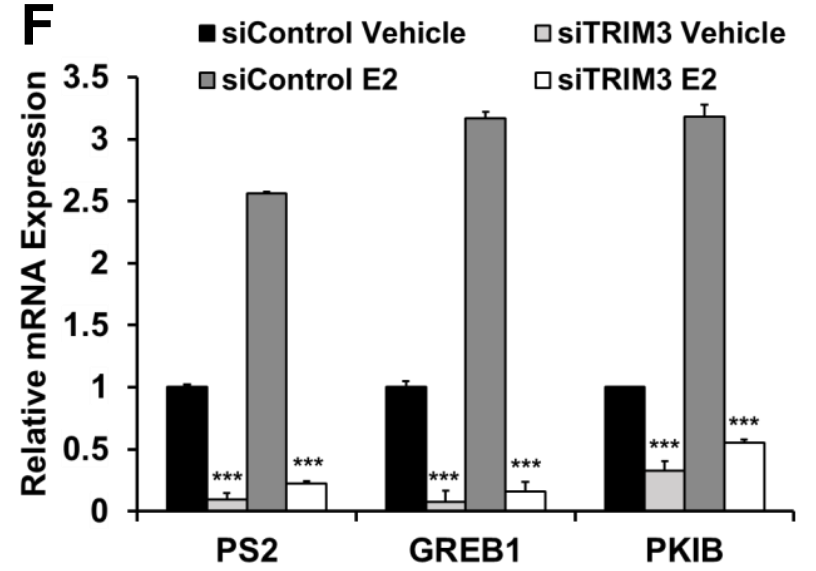

G

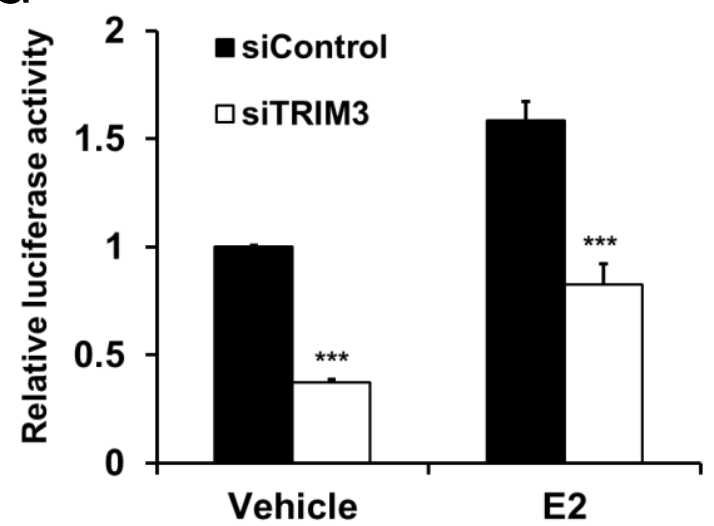




\section{Figure 3}

A

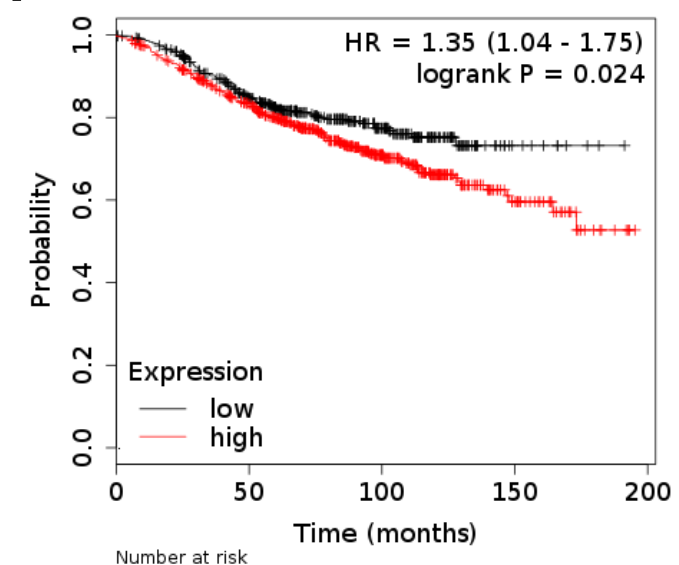

B

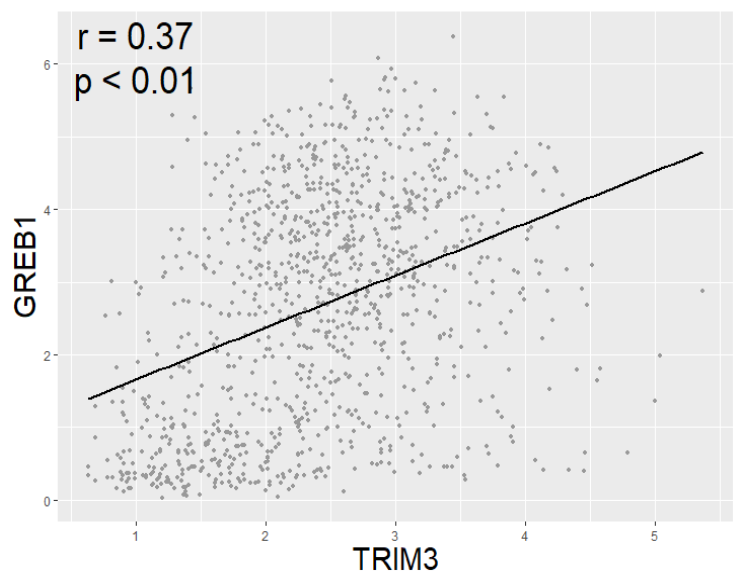

C

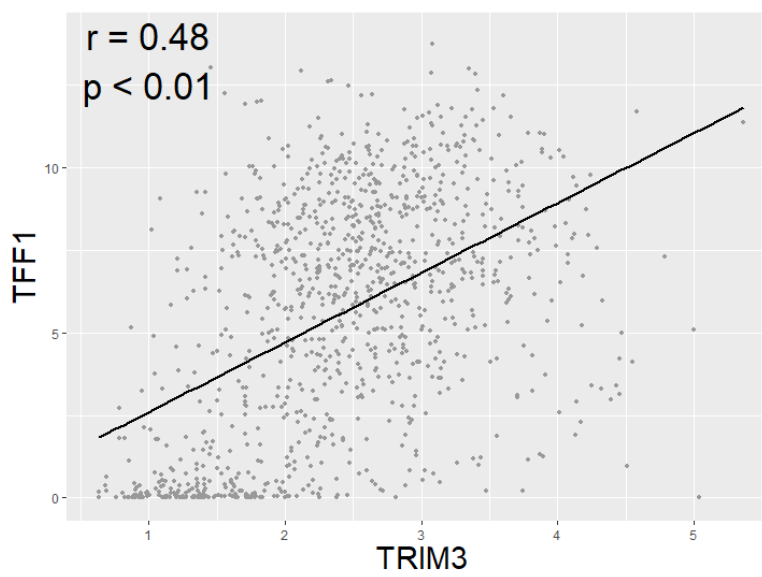

D

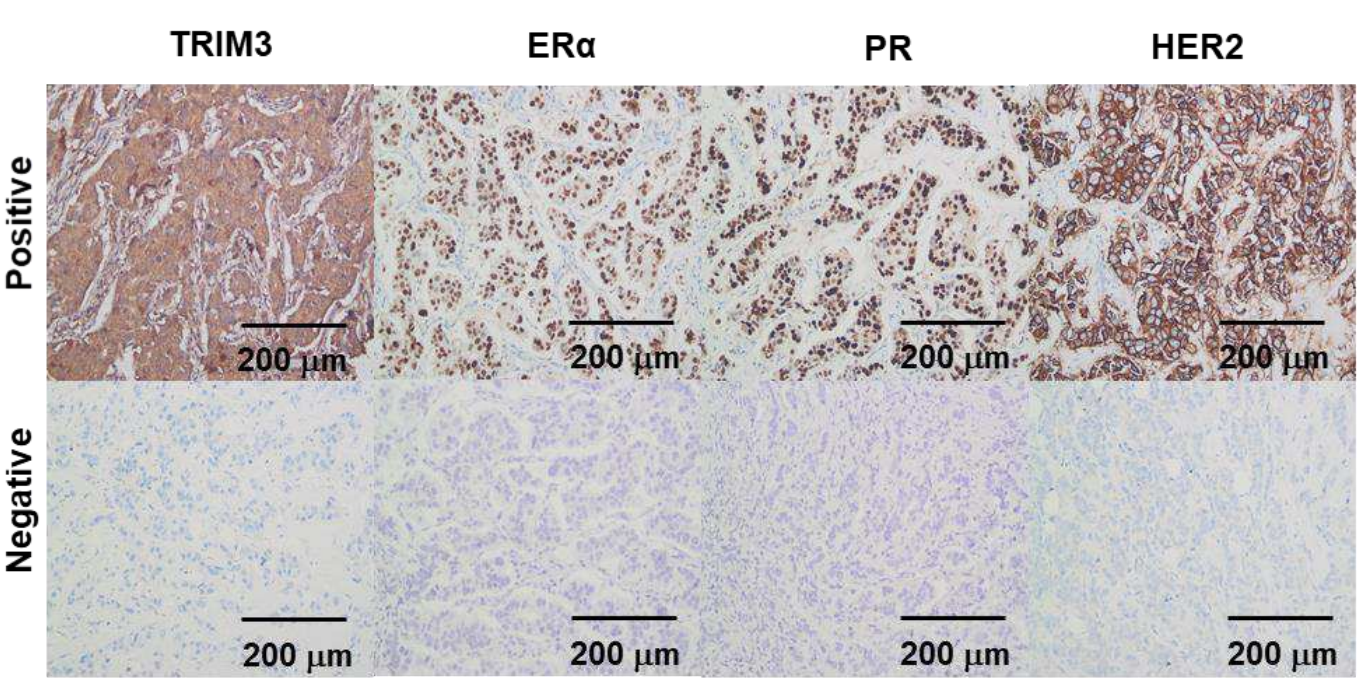

E

\begin{tabular}{|c|c|c|c|c|}
\hline \multicolumn{2}{|c|}{$\begin{array}{l}\text { Clinical and molecular } \\
\text { characteristics (Cases) }\end{array}$} & \multicolumn{2}{|c|}{ TRIM3 } & $P$ value \\
\hline \multirow{3}{*}{ ER $\alpha$} & & \multirow{2}{*}{+} & \multirow{2}{*}{21} & \multirow{3}{*}{$<0.001$} \\
\hline & + & & & \\
\hline & - & 22 & 26 & \\
\hline \multirow{2}{*}{ PR } & + & 54 & 13 & \multirow{2}{*}{$<0.001$} \\
\hline & - & 22 & 34 & \\
\hline \multirow{2}{*}{ HER2 } & + & 18 & 18 & \multirow{2}{*}{0.08} \\
\hline & - & 58 & 29 & \\
\hline \multirow{2}{*}{$\begin{array}{l}\text { lymph node } \\
\text { metastasis }\end{array}$} & + & 38 & 24 & \multirow{2}{*}{0.91} \\
\hline & - & 38 & 23 & \\
\hline \multirow{3}{*}{$\begin{array}{l}\text { pathological } \\
\text { grade }\end{array}$} & low & 3 & 0 & \multirow{3}{*}{0.04} \\
\hline & medium & 45 & 20 & \\
\hline & High & 18 & 27 & \\
\hline
\end{tabular}


A

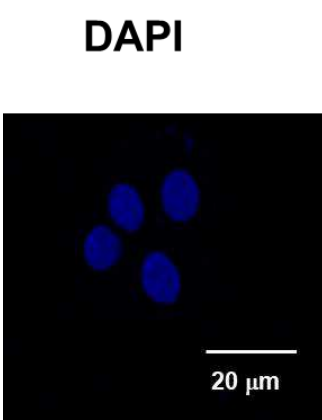

TRIM3

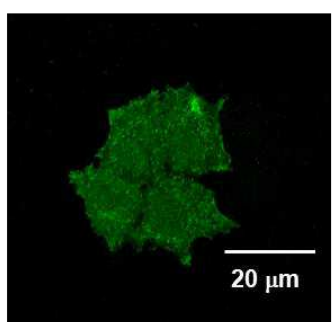

ERa

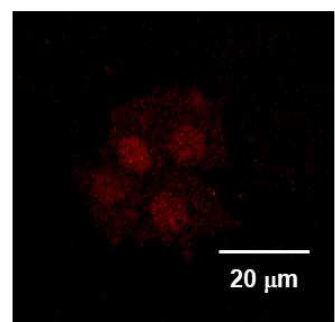

Merge

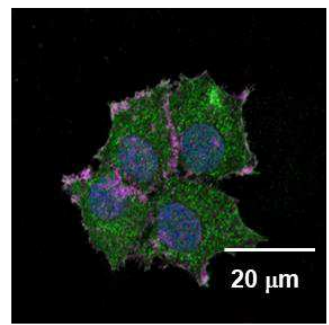

Input

B

WB:ERa

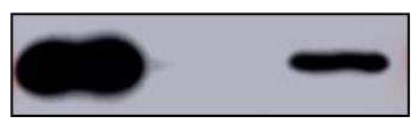

WB:TRIM3
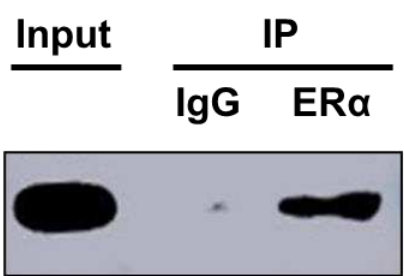

C

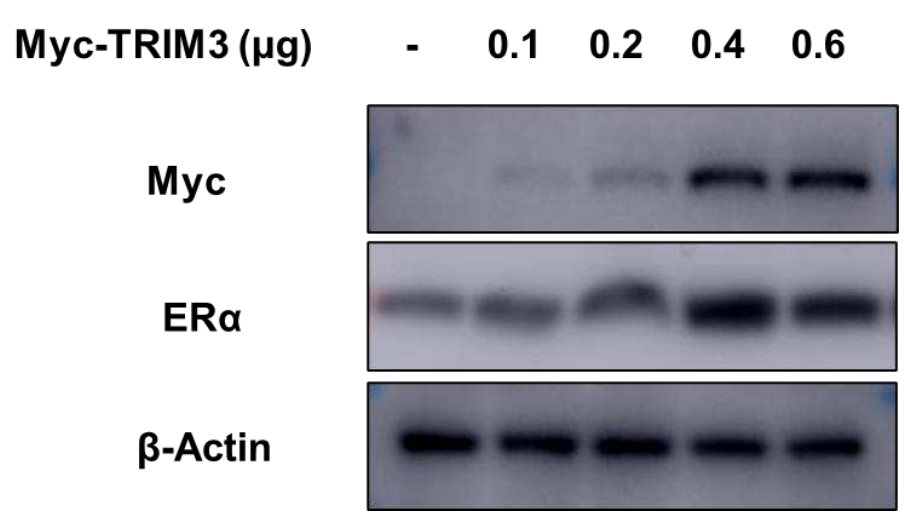

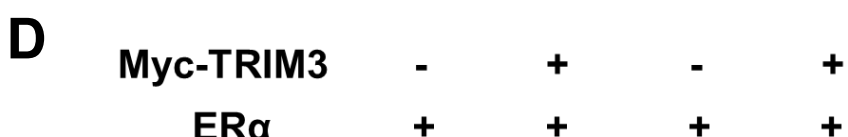

MG132 - $-+t^{+}$

E

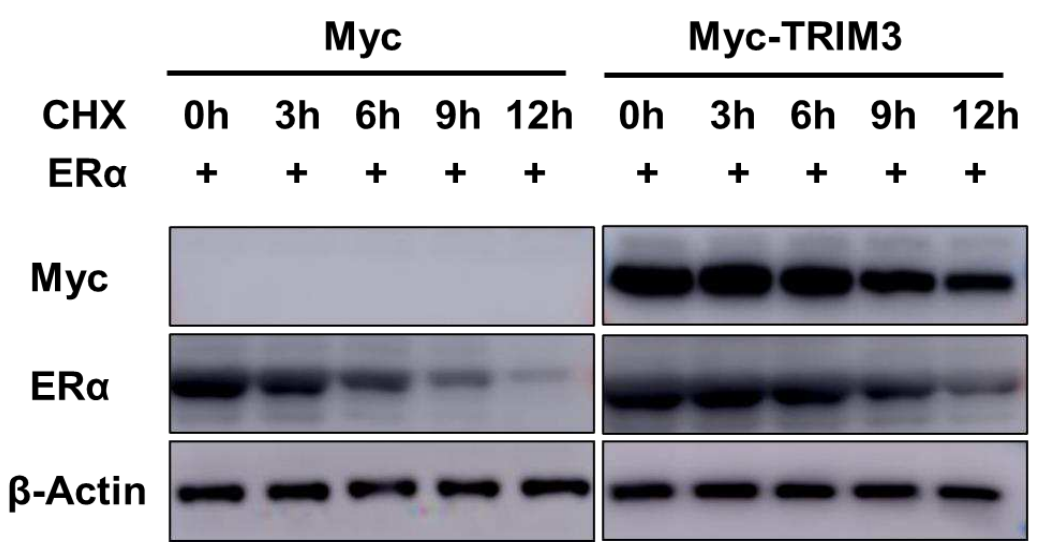

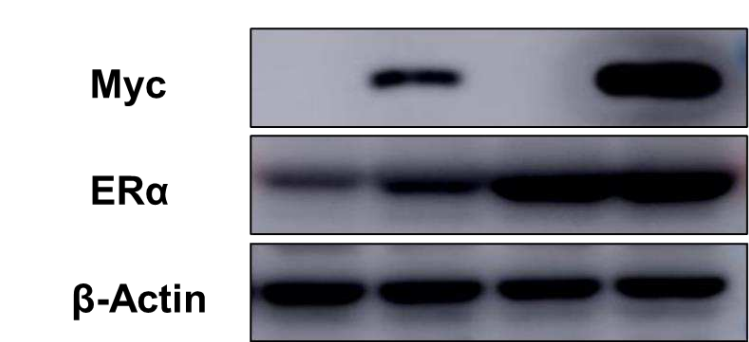

$\mathbf{F}$

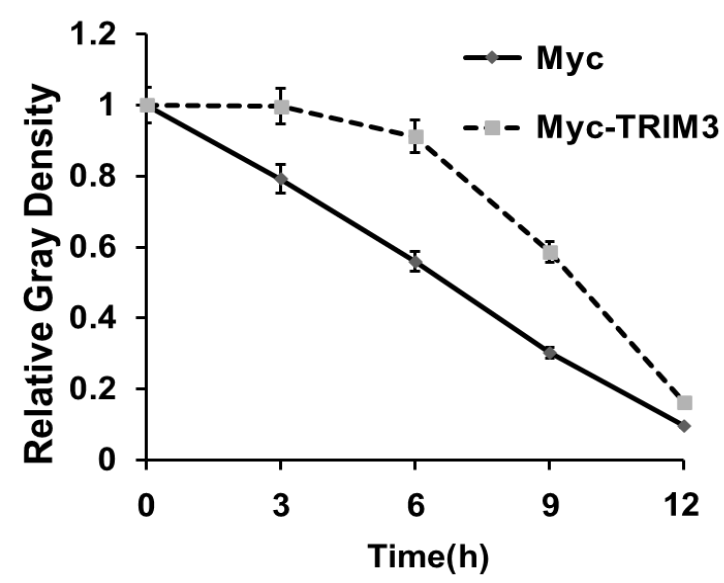




\section{Figure 5}

A ERa

A

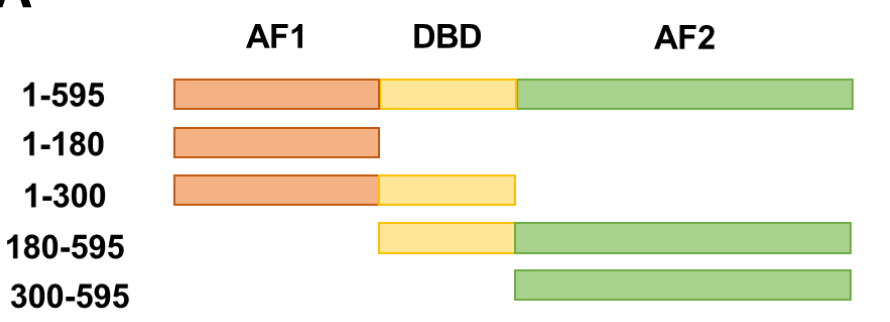

TRIM3

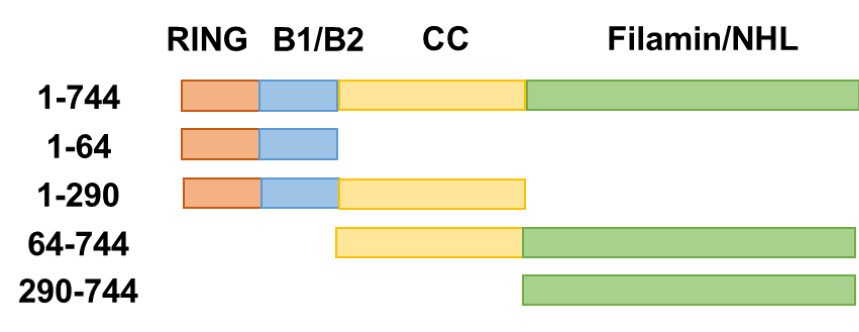

D

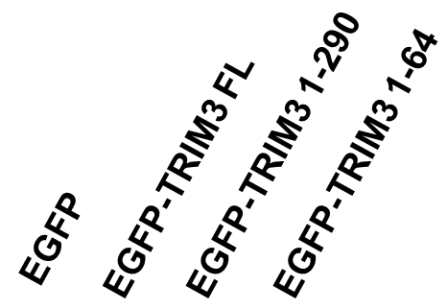

HA-ERa $+++\quad+$

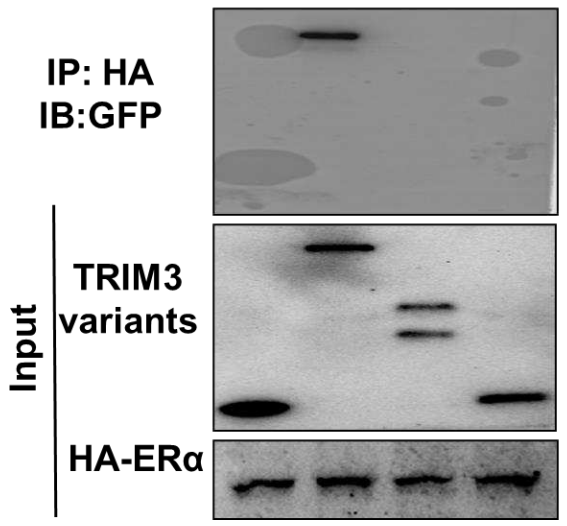

B
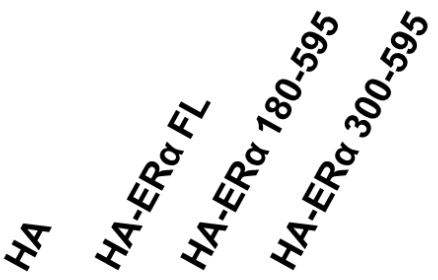

Myc-TRIM3 +

$+$

- IP: Myc

IB: HA
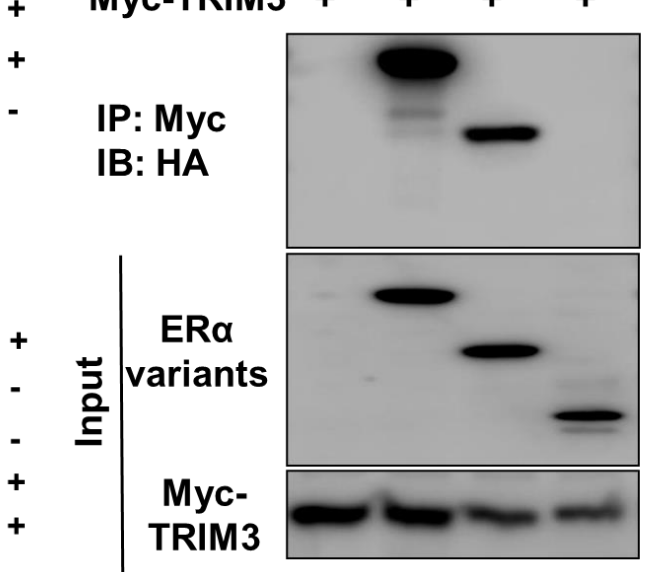

C

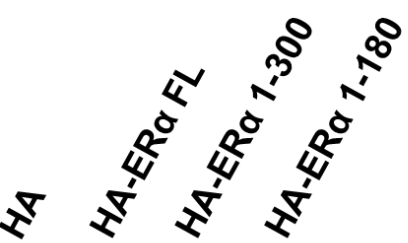

Myc-TRIM3 + + + +

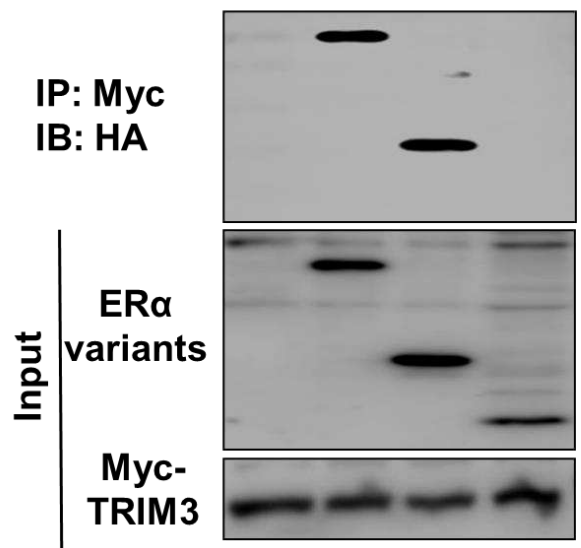

E
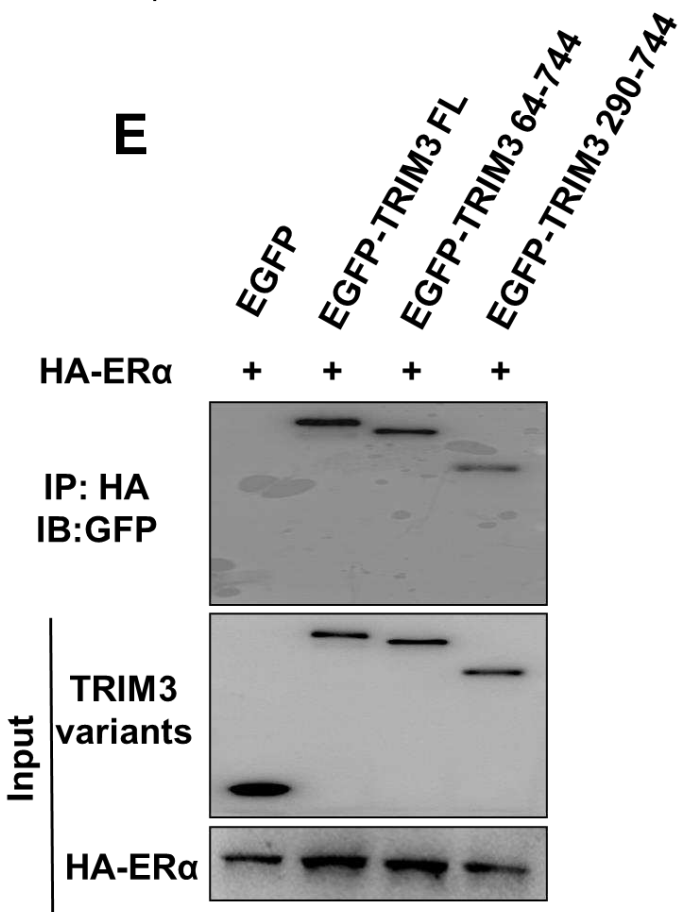

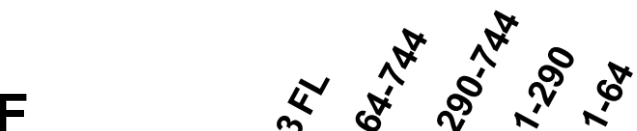

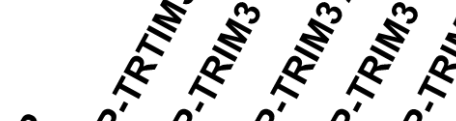

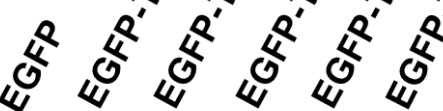

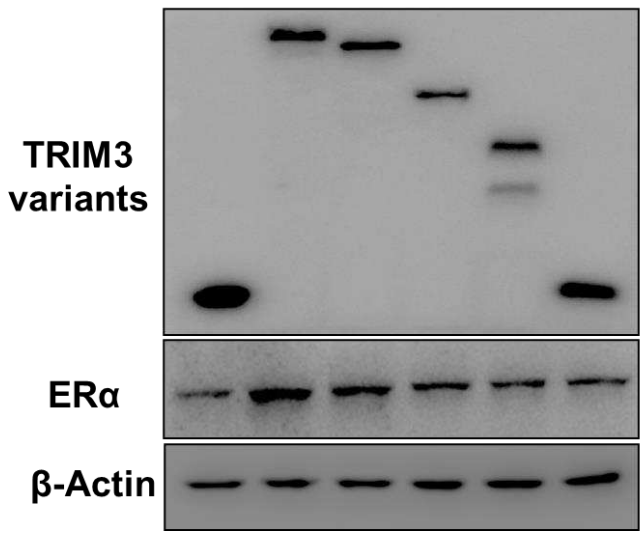




\section{Figure 6}
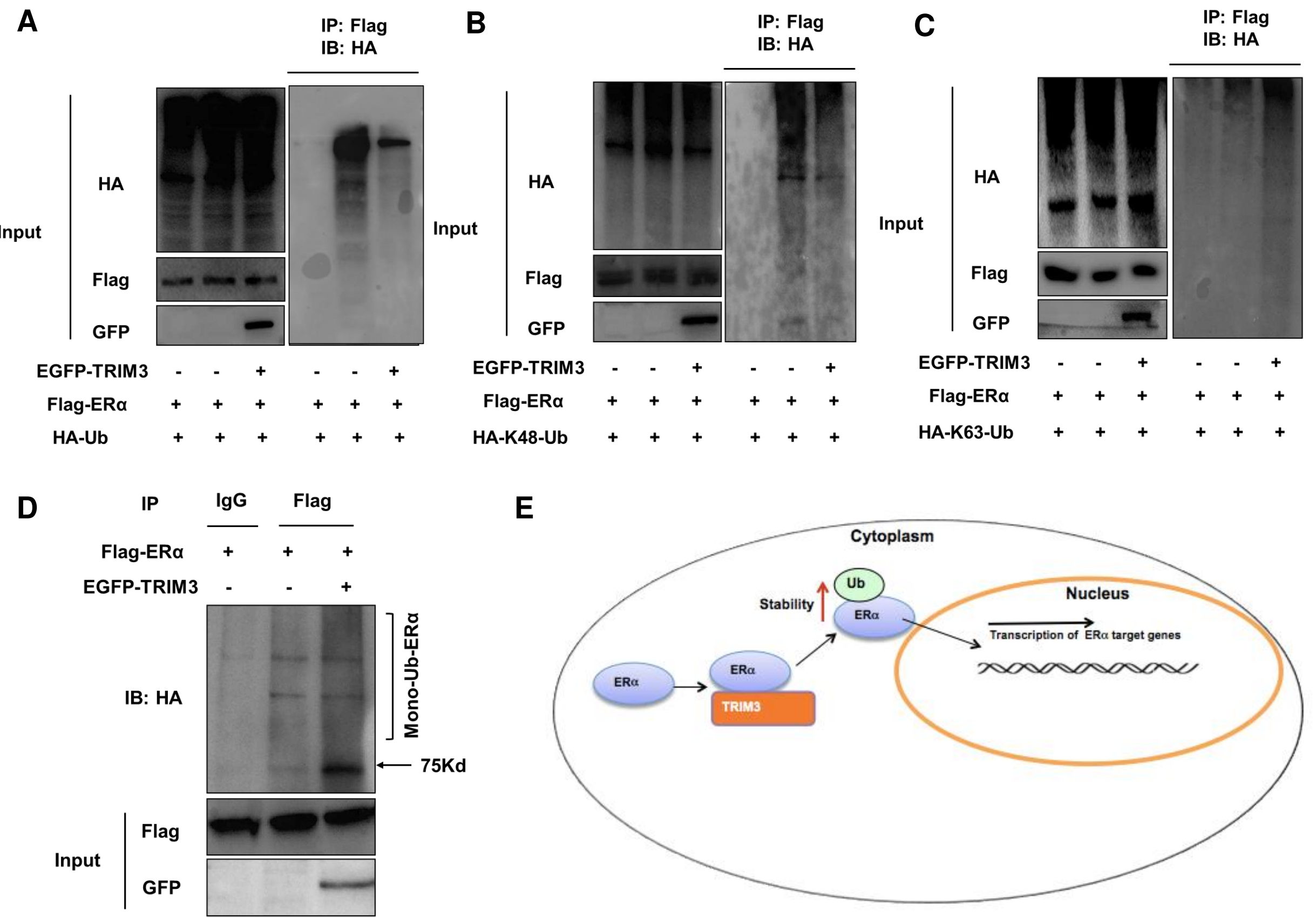